\title{
A quantitative approach to assessing the profitability of car and truck tire remanufacturing
}

\author{
Baptiste Lebreton*, Axel Tuma \\ Chair of Production and Environmental Management, University of Augsburg, Universitätsstr. 16, Augsburg 86135, Germany
}

\begin{abstract}
Over 600,000 tons of used tires are annually disposed of in Germany. Given the legal framework and the limited landfill capacities, particular attention has been given to the environmental impacts of tire recycling. Dedicated life cycle assessments point out tire remanufacturing, also called retreading, as the most sustainable recovery alternative. Nevertheless, retreading still remains only one alternative among others with a fraction varying from $1 \%$ up to $80 \%$ market share depending on the tire type. Thus, the primal purpose of this case study is twofold: to ascertain the reasons for such discrepancy and to investigate to what extent remanufacturing activities could be extended. This first requires an analysis of the present situation in both car and truck tire markets. In the following, we apply an OEM-centered decision model in order to analyze potential future scenarios concerning their ability to raise remanufacturing rates. We find out that retreaded truck tires have exhausted their remanufacturing potential whereas a customer-sided bottleneck hinders further development in the car tire market. Finally, we conclude that the question whether an OEM should add retreaded tires to his current product mix mostly depends on a product's nature, either functional or psychosociological. Only functional products have enough remanufacturing potential to justify an extension of supply chain planning towards recovery.
\end{abstract}

Keywords: Remanufacturing; Reverse logistics; Recovery; Planning; Supply chain management

\section{Introduction}

Over 600,000 tons of scrap tires are yearly disposed of in Germany (see IFEU, 1999). Since the German Recycling Law (KrW/AbfG), intro-

\footnotetext{
*Corresponding author. Tel.: + 4908215984357.

E-mail addresses: baptiste.lebreton@wiwi.uni-augsburg.de (B. Lebreton), axel.tuma@wiwi.uni-augsburg.de (A. Tuma).
}

duced in 1994 (see KrW-/AbfG, 2001), particular attention has been given to the disposal phase. This legislation compels OEMs to ensure the recycling of their products although the German Recycling Law presents a framework that does not specifically apply to tire manufacturers. Recent studies investigate the ecological impact of tire recycling processes. The consequences of such life cycle assessments should not be underestimated as 
they point out the resource efficiency of recycling processes. In case the German Recycling Law is applied to the tire industry, the most sustainable recycling processes would be explicitly preferred and, if necessary, enforced by setting reintegration targets, similar to the automobile industry. By now, no regulation explicitly compels OEMs to close their supply chain at the component level. Hence, without direct legislative pressure, it can be expect that remanufacturing programs will be solely driven economically.

In order to comprehend the challenges appearing during the recycling process, a brief overview of a tire's material composition is necessary. The following (Fig. 1) shows the average material breakdown of a tire.

About $45 \%$ of a tire consist of rubber compounds and $25 \%$ of carbon black. This composition makes tires inappropriate for landfill because of their inflammability and tendency to find their way back up to the surface after having been buried. However, this dumping problematic is not critical since, with a calorific value of $31,000 \mathrm{~kJ} / \mathrm{kg}$, used tires are an appreciated input for incineration processes. In fact, as shown is Fig. 2, approx. 50\% of scrap tires are used as a supply for the German Portland cement kilns. Advantages of this approach are manifold: first, rubber combustion generates heat, moreover, incineration residues serve as an input into the cement production without leading to quality loss. Namely, the

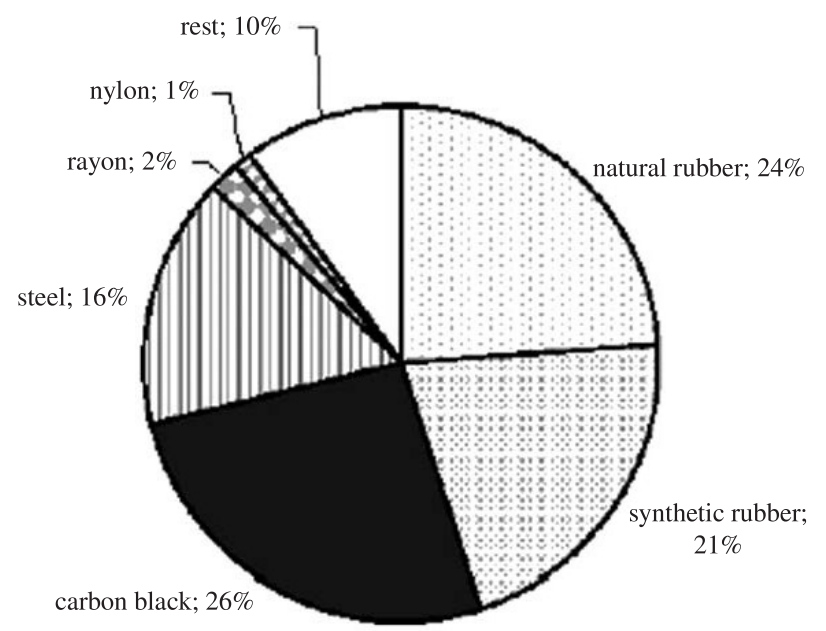

Fig. 1. Average material composition of a tire (IFEU, 1999).

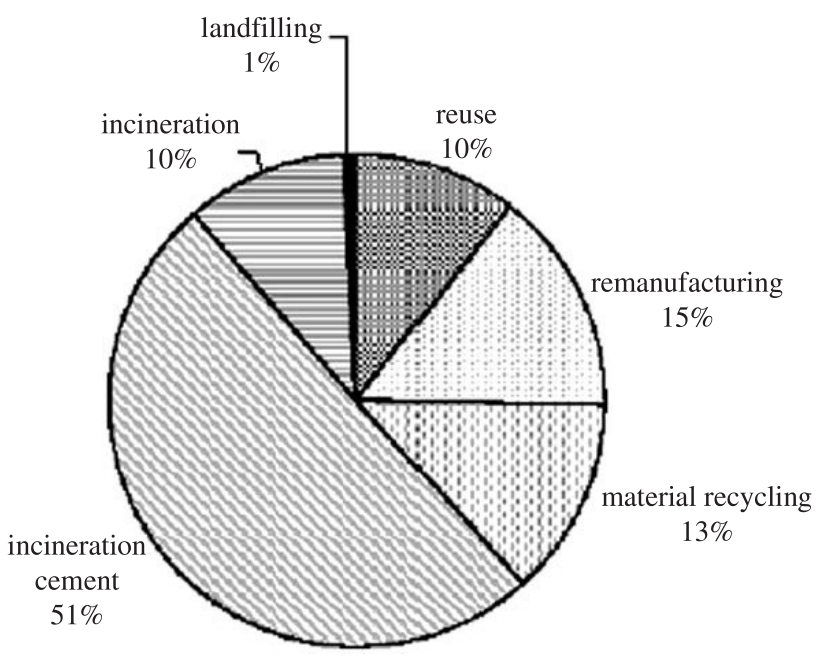

Fig. 2. Allocation of scrap tires to recovery alternatives (IFEU, 1999).

reclaimed steel can substitute iron which is usually required for Portland cement. Dedicated thermoelectric plants present another energy reclaiming alternative (see Ferrer, 1997; IFEU, 1999). In both cases, used tires lead to significant resource savings as tires either replace raw materials such as coal (Portland cement) or avoid generation of further KWh through oil, gas or nuclear power. Considering raw material prices, this substitution also leads to significant financial savings for plants that apply this recycling approach. Nevertheless, energy reclaiming, despite its resource savings, is not sustainable in the long run as it utilizes only nonrenewable materials (except for natural rubber).

Unlike incineration, material recycling represents an opportunity to keep resources in the supply chain. The composition of a tire indicates that the processing output mostly consists of granulated rubber; nevertheless, the limits of recycling become clear when considering the reintegration possibilities of reclaimed rubber. The vulcanization process which causes a crosslinking of rubber molecules is not reversible. It is therefore not possible to manage a further molecular bond with other rubber mixes. As a result, a satisfactory chemical cohesion cannot be attained when using reclaimed rubber, therewith limiting its use to tire parts that do not underlie above-average stress (quality requirements exclude reclaimed rubber from high-end tires) or in which 
virgin rubber does not overperform (connections of rubber to metal). Because of these limitations, the rubber reintegration scope will remain low. Investigations mandated by the German environmental administration, among other by IFEU (1999), estimate an upper-bound reaching up to a $1.5 \%$ of a tire's weight. Experts do not expect this figure to increase in the near future.

Considering the material limits of rubber recycling, downcycling appears unavoidable, i.e. rubber can only be processed into different, lowergrade applications such as a bitumen additive in order to extend the service life of the road surface. ${ }^{1}$ Nevertheless, two objections can be raised against downcycling despite its contribution to resource replenishment: firstly, the German market for scrap rubber is already saturated; secondly, this kind of recycling has no impact on the initial resource consumption in the tire supply chain.

So far, it has been difficult to identify a sustainable way to recover resources from used tires. As a matter of fact, Ferrer (1997), Ayres et al. (1997) and IFEU (1999) instead agree about the overwhelming resource savings reached by tire remanufacturing, also commonly depicted as retreading. In this context, Ayres et al. point out that retreading is the only way to partly retain a tire's added value which represents about $80 \%$ of the production costs. Material recycling or incineration can only recover less than $3 \%$ of a tire's value. A look at the life cycle assessment dealing with tire recycling strengthens these findings: the production of a retreaded car tire, for instance, consumes only one third of the energy input and one fourth of the material input required for a brand new tire (see Table 1).

A look at the product structure is necessary to understand the overwhelming ecological merits of retreading. A generic tire is composed of several elements that can be aggregated into two parts: casing and tread. Due to its continuous contact with the road surface, a tread wears out and tends to become flat, then causing insufficient road adherence and reduced braking performance. Fortunately, tires are returned although the tire

\footnotetext{
${ }^{1}$ The additional elasticity of rubber compounds helps extend the surface's service life.
}

Table 1

Resource consumption for the production of a car tire, see Ferrer (1997)

\begin{tabular}{lll}
\hline Tire type & Energy (in kJ) & Materials (in kg) \\
\hline New & 72,000 & 8 \\
Retreaded & 19,000 & 1.9 \\
\hline
\end{tabular}

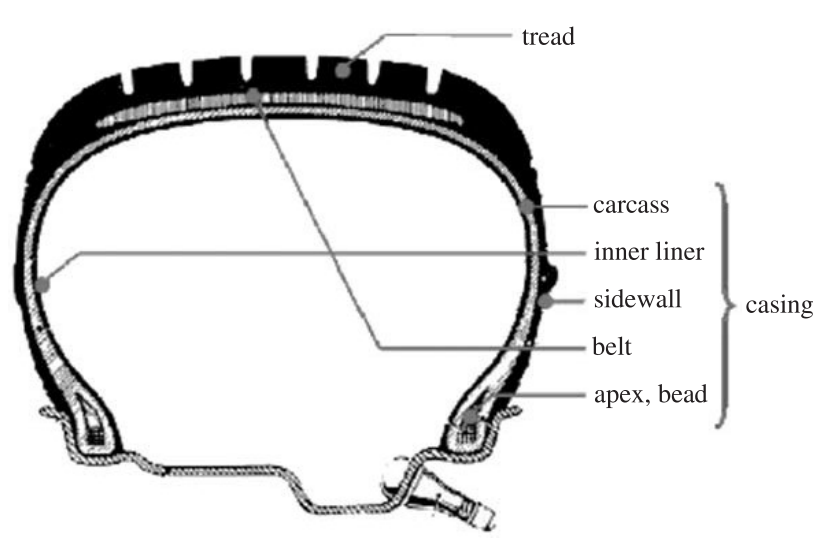

Fig. 3. Tire structure.

casing often presents no significant damage: tire casings are, in fact, not considered as wear parts since their wear pattern is not linked to the tire's service life but the users driving style (Fig. 3).

Roughly speaking, retreading means replacing the worn tread with a new one. To be remanufactured, a tire has to pass several steps beginning with an initial inspection where damaged casings are filtered out. The disassembly process consists of removing the worn tread with help of a buffing rasp and thus preparing the casing for the application of a new tread. As a next step, both parts are bonded during the vulcanization process. At this point, the remanufacturer faces the choice between two types of bonding techniques: mold cure (with an uncured tread subsequently molded) and precure (with an already cured tread fixed by a special bonding rubber).

Despite the evidential merits of retreading on an economical as well as ecological level, remanufacturing rates are varying significantly among tire types, as shown in Table 2. All published studies so far agree that the remanufacturing potential of 
Table 2

Tire remanufacturing rates

\begin{tabular}{ll}
\hline Tire type & Remanufacturing rate (\%) \\
\hline Summer car tire & 1 \\
Winter car tire & 10 \\
Light truck tire & 17 \\
Truck tire & 50 \\
Airplane tire & Up to 90 \\
\hline
\end{tabular}

Source: IFEU (1999) and Ferrer (1997).

truck and airplane tires is already exhausted. At a first glance, however, the discrepancy between summer car tires and airplane tires is hard to explain since material composition and the retreading technology applied do not significantly differ. This provides an interesting basis for investigating the reasons explaining such an unbalanced situation.

\section{A quantitative model for assessing the profitability of remanufacturing}

As stated above, further development of remanufacturing will be mostly justified economically and partly OEM-driven. OEMs' efforts to limit the remanufacturability of their products (for instance by toner cartridges) might be very restricted through environmental and legislative pressure in the long run. The question whether remanufacturing is profitable for a given product still remains hard to answer a priori.

Guide and Van Wassenhove (2001) and Ayres et al. (1997) identify a wide range of success factors, which are expected to have a positive influence on remanufacturing operations. However, the inherent complexity of remanufacturing issues might not have its origins in the variety of factors but in the interactions between them. Recent publications from Geyer and Van Wassenhove (2002) as well as Lebreton and Tuma (2003) point out three main interacting parameters in this context:

- Market segmentation. The presence of a sufficient demand for reclaimed goods is a prerequisite for component reuse.
- Return flow structure. Rogers and TibbenLembke (1999) list several types of reverse flows, among others: commercial returns, defective products or parts and end-of-life returns. Despite the diversity of flows with respect to their timing and quality, one may conclude that an early return timing is usually favorable to obtain reusable cores.

- Reintegration potential. Technological and functional obsolescence hinder further reuse of components. Firstly, frequent technology shifts exclude aged components from reintegration; secondly, wearing makes some parts inapt for repairing or upgrading.

The following decision LP-model therefore encompasses these three key factors as well as monetary parameters to gain first insights into the financial impact of remanufacturing. The choice of linear programming as support for our investigations, instead of simulation or agent-based systems, has one main reason: we want to find out directly which sales mix is optimal for the OEM with respect to parametric constraints. The lack of data considering customers' behavior and the necessity of delivering quantifiable results for OEMs makes the use of agent-based systems very difficult. We consider an OEM acting as a monopolist on his market which goal is to obtain a profit maximizing product mix that also includes remanufactured products. This model is kept in its generic form in order to enable its matching with other case studies. Its purpose is to cluster the products into weak and strong remanufacturing candidates. Obviously, strong remanufacturing candidates are ought to improve an OEMs overall financial performance. Fig. 4 illustrates the models flows and their interactions.

$$
\begin{array}{ll}
\text { Index } & \text { sets } \\
c & \text { set of components } \\
p & \text { set of products } \\
q & \text { set of quality levels } \\
t, t^{\prime} & \text { set of time periods }
\end{array}
$$

Variables

$\beta_{p, q, t} \quad$ market share of product $p$ in segment $q$ during period $t$ 


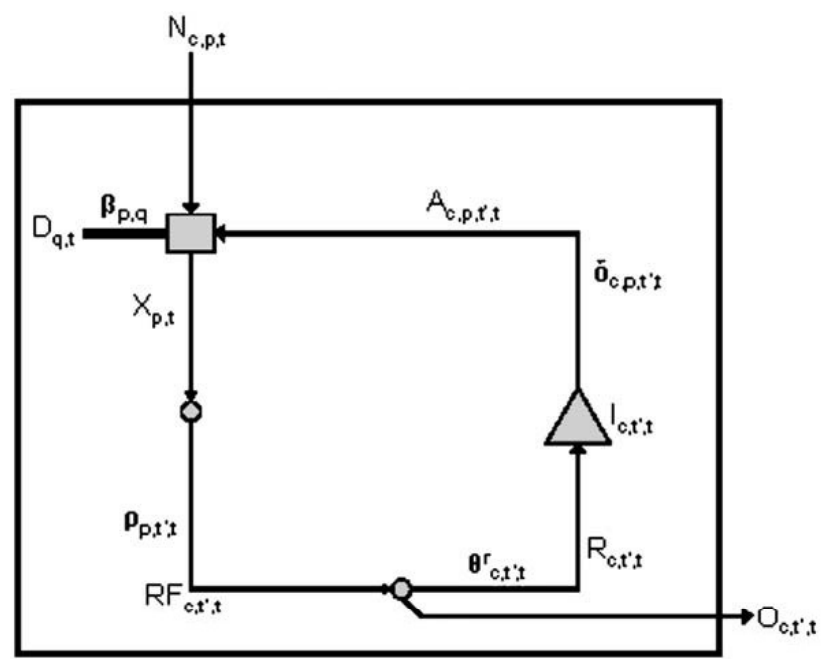

Fig. 4. Model overview.

$X_{p, t} \quad$ flow of produced good $p$ in period $t$

$N_{c, p, t} \quad$ flow of new components $c$ during period $t$ used to produce item $p$

$A_{c, p, t^{\prime}, t} \quad$ flow of reused components $c$ in product $p$ of period $t^{\prime}$ into period $t$ (remanufacturing or spare part)

$\mathrm{RF}_{c, t^{\prime}, t}$ reverse flow of component $c$ of period $t^{\prime}$ into period $t$

$R_{c, t^{\prime}, t}$ reintegrated flow during period $t$ of component $c$ introduced in period $t^{\prime}$

$O_{c, t^{\prime}, t} \quad$ flow of components $c$, aged $t-t^{\prime}$, leaving the system

\section{Profits/costs}

$\pi_{p, t} \quad$ selling price of product $p$ in period $t$

$c_{p, t}^{P} \quad$ variable cost per unit of manufacturing product $p$ in period $t$

$c_{c, p, t}^{N} \quad$ cost of a new component $c$, integrated into product $p$ during period $t$

$c_{c, t^{\prime}, t}^{\mathrm{RF}} \quad$ reclaiming costs for component $c$ issued from end-of-life product return flows after $t-t^{\prime}$ periods (acquisition, transportation, disassembly)

$c_{c, t^{\prime}, t}^{R} \quad$ recovery costs for component $c$ of period $t^{\prime}$ into period $t$ (testing, cleaning, repair)

$c_{c, t^{\prime}, t}^{O} \quad$ recycling cost for component $c$, sold in period $t^{\prime}$

$c_{c, t^{\prime}, t}^{I} \quad$ holding cost for part $c$ aged $t-t^{\prime}$ periods

\section{Parameters}

$D_{q, t} \quad$ demand of service units from quality $q$ during period $t$

$\alpha_{c, p} \quad$ sourcing matrix, number of components $c$ in product $p$

$\beta_{p, q}^{\max } \quad$ upper bound for market share of product $p$ in segment $q$

$\rho_{p, t^{\prime}, t} \quad$ return probability of product $p$, sold in period $t^{\prime}$, during period $t$

$\theta_{c, t^{\prime}, t}^{r} \quad$ working probability of part $c$ returned after $t-t^{\prime}$ periods of use (no worn part)

$\delta_{c, p, t^{\prime}, t}$ binary indicator allowing the reuse option of component $c$ in product $p$ after $t-t^{\prime}$ periods of use

\subsection{Objective function}

$$
\begin{aligned}
\operatorname{Max} ! & \sum_{p, t} \pi_{p, t} \cdot X_{p, t}-\sum_{p, t} c_{p, t}^{P} \cdot X_{p, t} \\
& -\sum_{c, p, t} c_{c, p, t}^{N} \cdot N_{c, p, t}-\sum_{c, t^{\prime}, t} c_{c, t^{\prime}, t}^{\mathrm{RF}} \cdot \mathrm{RF}_{c, t^{\prime}, t} \\
& -\sum_{c, t^{\prime}, t} c_{c, t^{\prime}, t}^{R} \cdot R_{c, t^{\prime}, t}+\sum_{c, t^{\prime}, t} c_{c, t^{\prime}, t}^{O} \cdot O_{c, t^{\prime}, t} \\
& -\sum_{c, t^{\prime}, t} c_{c, t^{\prime}, t}^{I} \cdot I_{c, t^{\prime}, t} .
\end{aligned}
$$

The producer's goal is to maximize the contribution margin with a given selling price $\pi_{p, t}$ for a good $p$ in period $t$ on the one hand, and thereby minimize the costs induced by production, components procurement, reclaiming, recovery and disposal on the other hand. Although selling prices for remanufactured products are generally lower than those for new ones, the marginal income per remanufactured unit might be higher thanks to savings on the cost side.

The diversity of reverse logistics processes makes it difficult to encompass each specificity of a supply chain; therefore, we have limited the cost parameters to two generic data sets: $c_{c, t, t}^{\mathrm{RF}}$ and $c_{c, t, t}^{R}$. $c_{c, t, t}^{\mathrm{RF}}$ encompasses all process costs required to make a component available, i.e. acquisition costs, transportation and disassembly. $c_{c, t, t}^{R}$ comprises the postponed steps which are necessary to ensure the component's reintegration into the production or utilization process (sorting, testing, cleaning and 
upgrading). This aggregation level allows a flexible adaptation to the single remanufacturing cases.

\subsection{Constraints}

$X_{p, t}=\sum_{q} D_{q, t} \cdot \beta_{p, q, t}, \quad \forall p, t$,

$\sum_{p} \beta_{p, q, t}=1, \quad \forall q, t$,

$\beta_{p, q, t} \leqslant \beta_{p, q}^{\max }, \quad \forall p, q$.

Eq. (1) expresses the matching of customers' needs in a given segment with the supplied products (e.g. for cars: the demand for superior quality with upto-date technology matches with a new premium car). Variable $\beta_{p, q, t}$ also describes a product's market share in a specific segment and period. Since $\beta_{p, q, t}$ is variable, Eq. (2) ensures that the sum of all market shares in a segment q reaches $100 \%$ whereas Eq. (3) sets a potential upper-bound $\beta_{p, q}^{\max }$ for a market share. This restriction especially applies to remanufactured items which face psychological obsolescence. Depending on the market structure, a product may compete in several market segments: remanufactured toner cartridges, for instance, partly cannibalize the demand for new OEM cartridges.

$$
\begin{aligned}
& \mathrm{RF}_{c, t^{\prime}, t}=\sum_{p} \alpha_{c, p} \cdot X_{p, t^{\prime}} \cdot \rho_{p, t^{\prime}, t}, \quad \forall c, t^{\prime} \leqslant t, t, \\
& \mathrm{RF}_{c, t^{\prime}, t}=R_{c, t^{\prime}, t}+O_{c, t^{\prime}, t}, \quad \forall c, t^{\prime} \leqslant t, t, \\
& R_{c, t^{\prime}, t} \leqslant \theta_{c, t^{\prime}, t}^{r} \cdot \mathrm{RF}_{c, t^{\prime}, t}, \quad \forall c, t^{\prime} \leqslant t, t .
\end{aligned}
$$

Eq. (4) computes the product returns with help of the reverse flow distribution $\rho_{p, t, t}$. Eq. (5) expresses the fact that returned parts $\mathrm{RF}_{c, t, t}$ are either disposed of (i.e. landfilled or recycled) or processed for reuse $\left(R_{c, t, t}\right)$. In Eq. (6), the reintegrated cores $R_{c, t, t}$ are limited by parameter $\theta_{c, t, t}^{r}$ which takes into account that some of the reclaimed cores, depending on their origin and age, may be too worn or damaged to be reintegrated.

$$
I_{c, t^{\prime}, t-1}+R_{c, t^{\prime}, t}=I_{c, t^{\prime}, t}+\sum_{p} A_{c, p, t^{\prime}, t}, \quad \forall c, t^{\prime} \leqslant t, t,
$$

$A_{c, p, t^{\prime}, t} \leqslant \delta_{c, p, t^{\prime}, t} \cdot\left(I_{c, t^{\prime}, t-1}+R_{c, t^{\prime}, t}\right), \quad \forall c, p, t^{\prime} \leqslant t, t$,

$\alpha_{c, p} \cdot X_{p, t}=N_{c, p, t}+\sum_{t^{\prime} \leqslant t} A_{c, p, t^{\prime}, t}, \quad \forall c, p, t$.

Eq. (7) allows for storing parts that can be reused in later periods. Eq. (8) sets an upper-bound for component reintegration, whereby flow $A_{c, p, t^{\prime}, t}$ comprises only parts that are technologically reusable. The key factor and binary parameter $\delta_{c, p, t, t}$ indicates which sourcing combinations are allowed, i.e. in which product a given component $c$ can be reused after $t-t^{\prime}$ periods. Finally, Eq. (9) computes the overall part demand which is either accommodated by new parts $\left(N_{c, p, t}\right)$ or reclaimed ones $\left(A_{c, p, t^{\prime}, t}\right)$.

\section{Case study: tire industry}

\subsection{Index sets}

The first step in order to implement the model is to define an index set that respects the existing trade-off between accuracy and complexity. The model should therefore be dimensioned as concise as possible without compromising its fit for reality. The trade-off can be illustrated by the dimensioning of the component set $C$ in which seven different tire parts can be taken out of Fig. 3. We mentioned that these can be aggregated into a casing ${ }^{2}$ and a tread. This dimension reduction by two-third has no consequence on the results as retreading processes are only concerned with the separation of casing and tread and never aim at reclaiming parts embedded in a casing.

We focus our analysis on two generic tire dimensions which are widely spread in Germany: P175/65R $14^{3}$ for car tires and 295/80R22.5 for truck tires. Albeit the diversity of tire producers, it is possible to group the market actors into four homogeneous clusters: high-end, middle-range

\footnotetext{
${ }^{2}$ The casing encompasses carcass, inner-liner, sidewall, belt, apex and bead.

${ }^{3} \mathrm{P}$ : passenger car tire, 175: $\operatorname{section}(=$ tire) width in $\mathrm{mm}, 65$ : aspect ratio in $\%$ (section height/section width), R: radial construction, 14: rim diameter in inches.
} 
Table 3

Demand segmentation of tire markets in Germany (see Bundesverband and Vulkaniseur, 2000, 2001)

\begin{tabular}{|c|c|c|c|}
\hline Segment & Summer car tires & Winter car tires & Truck tires \\
\hline \multirow[t]{2}{*}{ Premium } & \multicolumn{3}{|c|}{ e.g. Continental, Michelin, Goodyear, Bridgestone, Pirelli } \\
\hline & $39.5 \%$ & $35.5 \%$ & $36 \%$ \\
\hline \multirow[t]{2}{*}{ Budget } & \multicolumn{3}{|c|}{ e.g. Uniroyal, Dunlop, Vredestein, Pneumant, Kleber, Fulda, Semperit } \\
\hline & $38.5 \%$ & $39.5 \%$ & $18 \%$ \\
\hline \multirow[t]{2}{*}{ Low budget } & \multicolumn{3}{|l|}{ e.g. Sumho, Rigdom } \\
\hline & $22 \%$ & $25 \%$ & $46 \%$ \\
\hline
\end{tabular}

(MR), import and retreaded. Hence, we limit the models product set $\mathrm{P}$ to four items (one product for each group). According to our investigations, these four products are positioned into three partly coupled market segments $q$ : premium, budget and low budget (see $\mathrm{BRV}^{4} 2000$ (Bundesverband and Vulkaniseur, 2000)). The time frame for the observation encompasses 20 periods in order to respect the whole product life cycle of a tire. The period length thereby encompasses $\frac{1}{2}$ year for all tires.

\subsection{Key factors}

\subsubsection{Demand}

The findings from Table 3 are twofold. First, the demand for passenger car tires is nearly equivalent for premium as well as for budget tires. For psychological reasons explained further in this article, buyers prefer to avoid low budget tires. Unlike car tire buyers, truck tire buyers prefer either premium or low budget tires. Deierlein (1988) mentions that carriers prefer premium tires for the driving axle of their trucks, not solely because of security concerns but also because these tires are easier resold for retreading. Low segment tires are primarily used for trailers since these face tire failures to a lesser extent. As it is also reglementary forbidden to put retreaded tires on the front axle, the demand is clearly limited for these tires.

${ }^{4}$ BRV: Bundesverband Reifenhandel und Vulkaniseur Handwerk e.V.-German tire manufacturer lobby.
The value of $\beta_{p, q}^{\max }$, issued from own estimations and checked for correctness by the BRV, depicts the tire positioning in a segment $q$. An upper bound of 1 indicates that a good is clearly positioned in this segment while a value of 0 means the opposite. The small price gaps between segments (see Table 5) partly explains the porosity between segments. In the following, we observe an OEM covering a representative market with the four products depicted in Table 4. Due to the highly competitive environment and the existence of established segments, $\sum_{p} \beta_{p, q}^{\max }$ is close to one but keeps a realistic degree of freedom. Hence, an OEM cannot modify the demand structure significantly on a short run (Tables 4 and 5).

German tire retreaders argue that the present segmentation is more driven by psychological obsolescence than by real quality and reliability concerns. In fact, all tires produced in Germany must pass quality tests to be allowed in a given speed segment. Tires within the same speed class thereby have approximatively the same quality, no matter if they have been retreaded or not. Import tires, however, do not underlie these restrictions and can be placed into speed classes without strict reliability control by the German authorities. Furthermore, retreaded tires are produced for a maximal speed of $190 \mathrm{~km} / \mathrm{h}$ (speed class T) which represents a great hurdle since an important fraction of German motorways are not regulated by any speed limit. Drivers lobby agitations in reaction to a potential reduction of motorways speed limits have shown that premium and budget customers are keen on keeping the freedom to drive fast, even if only occasionally. 
Table 4

Product market share upper bounds in given segments

\begin{tabular}{|c|c|c|c|c|c|c|}
\hline \multirow{2}{*}{$\frac{\text { Product }}{\text { High-end }}$} & \multicolumn{2}{|c|}{ Summer car tires } & \multicolumn{2}{|c|}{ Winter car tires } & \multicolumn{2}{|l|}{ Truck tires } \\
\hline & Premium & 1 & Premium & 1 & Premium & 1 \\
\hline & Budget & 0.2 & Budget & 0.1 & Budget & 0.1 \\
\hline & Low-budget & 0 & Low-budget & 0 & Low-budget & 0 \\
\hline \multirow[t]{3}{*}{ Middle-range } & Premium & 0.1 & Premium & 0.1 & Premium & 0.1 \\
\hline & Budget & 1 & Budget & 1 & Budget & 1 \\
\hline & Low-budget & 0.2 & Low-budget & 0.2 & Low-budget & 0.3 \\
\hline \multirow[t]{3}{*}{ Import } & Premium & 0 & Premium & 0 & Premium & 0 \\
\hline & Budget & 0 & Budget & 0 & Budget & 0 \\
\hline & Low-budget & 0.8 & Low-budget & 0.8 & Low-budget & 0.8 \\
\hline \multirow[t]{3}{*}{ Retread } & Premium & 0 & Premium & 0 & Premium & 0 \\
\hline & Budget & 0 & Budget & 0 & Budget & 0.3 \\
\hline & Low-budget & 0.1 & Low-budget & 0.5 & Low-budget & 0.8 \\
\hline
\end{tabular}

Table 5

Average retail prices in Germany in Euros, ADAC (2002)

\begin{tabular}{llll}
\hline Product & $\begin{array}{l}\text { Summer car } \\
\text { tires }\end{array}$ & $\begin{array}{l}\text { Winter car } \\
\text { tires }\end{array}$ & Truck tires \\
\hline High-end & 72 & 80 & 385 \\
Middle-range & 50 & 55 & 324 \\
Import & 35 & 45 & 250 \\
Retread & 37 & 37 & 295 \\
\hline
\end{tabular}

Few information is publicly available concerning the procurement $\operatorname{costs} c^{N}$. Hence, we can solely access the resource input to obtain non-biased data and therefore rely on Ferrer's (1997) estimations of material and energy costs. On the basis of his calculations, we set for car tires a price of 13.50 Euros for the casing and 3.50 Euros for the tread. Truck tires 295/80R22.5 weigh approximatively $58 \mathrm{~kg}$ which represents about six times a car tire's weight. Due to the higher metallic fraction, material and energy costs rise to 98 Euros for a truck casing and 25 Euros for a corresponding tread. Compared with procurement costs, production costs remain in a modest range: whereas labor costs for premium and middle-range tires yield 2 Euros and import tires only 1 Euro, retreaded tires involve the highest labor costs with 4
Euros. ${ }^{5}$ According to a German retreader, labor costs of truck tire manufacturers are about seven times higher than the costs for car tire production. We apply this rule of thumb to assess manufacturing costs $c^{P}$ of truck tires.

\subsubsection{Return flow timing and quantities}

Both the car and truck tire industry have in common the lack of knowledge about return distribution. Nevertheless, aggregated estimations of BRV document the average age of a returned tire and the total number of tires that are recovered in Germany. Summer car tires are returned after 3.5 years, winter tires only after 4.85 years. As mentioned before, the average lifespan of a truck tire is up to 1.8 years.

Reclaiming costs $c^{\mathrm{RF}}$ can be divided into disassembly, collection and acquisition costs that are required to guide the cores into a retreader's pipeline. As we already suggested in the introduction, obtaining tires for remanufacturing is not necessarily easy since other industry sectors, especially cement kilns, are also interested in this reverse flow (see Fig. 2). Once again, the ascertain-

\footnotetext{
${ }^{5}$ Especially because of the bonding process for tread and casing (curing) as well as because of labor intensive quality controls processes.
} 
ment of prices for both car and truck tires is subject to different patterns. Whereas disassembly and collection costs are quite proportional to a tire's size (4 Euros for car tires, 14 Euros for a truck tire), only truck cores are traded on a vivid market where prices may yield up to 50 Euros for an original tire, 30 Euros for a tire retreaded once and 15 Euros for a tire already retreaded twice. Acquisition costs for used car tires will be ignored in the following.

\subsubsection{Reintegration potential}

A core declines in value as a result of constant wearing: the loss of material consistency and damages caused to the sidewall reduce the reintegration probability of a casing. Legislation has recognized these limitations and therefore forbids tires of more than 6 years (car tires) or 8 years in age (truck tires) for sale. Despite the lack of studies concerning reintegration probability distributions, we define the following distributions concerning parameter $\theta^{r}$ for the simulation:

$$
\begin{aligned}
& \theta_{\text {casing, } t^{\prime}, t}^{r} \\
& \quad= \begin{cases}\text { truck tires }: 0.9-\frac{t-t^{\prime}}{20}, & \forall 0 \leqslant t-t^{\prime} \leqslant 16, \\
\text { car tires : } 0.6-\frac{t-t^{\prime}}{20}, & \forall 0 \leqslant t-t^{\prime} \leqslant 12, \\
\text { else : } 0 .\end{cases}
\end{aligned}
$$

Furthermore, it is important to notice that these figures have been tested for plausibility by the German tire lobby (BRV) and a German tire retreader. In addition to wearing, technological restrictions further hinder the reuse of reclaimed casings. In the tire industry case, OEMs are not allowed to use recovered casings into tires that are labelled as new. Hence, we set the respective parameter $\delta$ as follows in order to enable recovered casings' use into retreaded tires $(\delta=1)$ and avoid their use into the production of original tires $(\delta=0)$ :

$\delta_{\text {casing,retread }, t^{\prime}, t}= \begin{cases}1, & \forall t \geqslant t^{\prime}, \\ 0, & \text { else. }\end{cases}$

Subsequently, reintegration efforts have to be performed to refresh the used carcass. After having removed the worn tread (buffing process), the casing is controlled and repaired for further use. The following processes, tread application, curing (binding of casing and tread) and final inspection, are included in the production costs for retreaded tires, therefore explaining the sensibly higher manufacturing costs for remanufactured tires. Reintegration costs are charged at 3 Euros for car tires and 8 Euros for truck tires. In case reverse flows are leaving the system, a fee of 10 , respectively 1 Euro is charged to OEMs. This corresponds to the transportation costs to a recycler.

\section{Optimization results}

In the following, we will analyze the selling activities of a representative OEM on the German tire market. We assume that this producer provides three products: a high-end tire targeted for the premium segment, a middle-range tire primarily addressing the budget customers and a cheap imported tire for the low-budget segment. By now, tire OEMs face no regulation related to the recovery of their products unlike in the automotive or computer industry where manufacturers have to finance the recovery of their products. Scenario 0 therefore computes an initial situation where the investigated OEM neither pays for reclaiming nor for disposal/recycling of his tires.

Subsequently to the introduction of a product stewardship law, an OEMs alternatives are twofold: scenario 1 consists of doing nothing, i.e. starting to pay a fee on every sold tire to be released from the obligation of recovering tires on his own. The OEM can alternatively choose an offensive recovery strategy, depicted in scenario 2, which consists of starting a remanufacturing program and, to this purpose, add retreaded tires to his product mix. The goodwill issued from the launch of environmental friendly goods gives the OEM a far more important degree of freedom concerning the obligations of product stewardship laws. Legislation may for instance allow OEMs to finance the recovery of all returns ex-post as opposed to scenario 1 in which the recovery fee is paid ex-ante on all sold tires. As a consequence, 


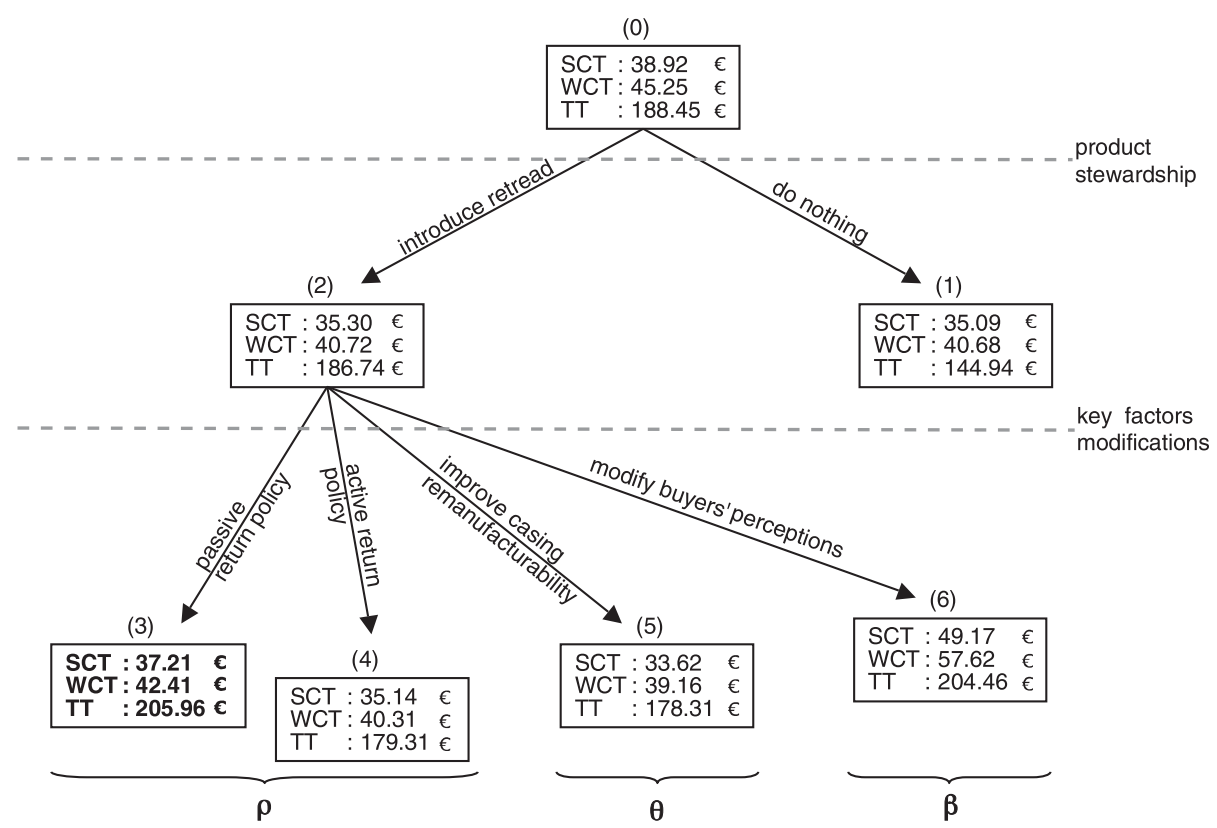

Fig. 5. Optimization results: contribution margin/tire sold.

system losses would not present a financial burden for the firm. Thus, scenario 3 computes the case where the OEM decides to sustain system loss, representing in this case $50 \%$ of the sold items, with help of a passive return strategy. Scenario 4 depicts a strategy opposite to scenario 3 since the producer obtains the tires back earlier, therefore enhancing the number of potentially reusable casings. This strategy, however, also increases the number of reclaimed used tires during the optimization horizon.

Instead of adapting parameter $\rho$ by means of an active return policy, one straightforward solution would be to improve the remanufacturability of a casing ceteri paribus by strengthening its sides, therefore requiring the use of more rubber. This case, depicted in scenario 5, leads to a $10 \%$ improvement of factor $\theta$ but also implies a material costs increase by $10 \%$ that cannot be shifted to the final customers. In the long run, a further possibility for the OEM might be to modify the demand structure (parameter $\beta$ ) through marketing actions. For this purpose, we compute in scenario 6 an optimal solution for the case where no market limitations $\left(\beta^{\max }\right)$ are present and obtain first advices about the products to promote preferentially. All scenarios have been computed in the same fashion for summer car tires (SCT), winter car tires (WCT) as well as truck tires (TT). The results are presented below (Fig. 5) in a normalized form: the objective function (equivalent to the overall contribution margin) has been divided by the number of tires sold to reach the average marginal income per tire. The corresponding market shares are documented in Table 6.

Subsequently to the introduction of a recycling fee, the marginal income per tire shrinks ceteri paribus by $10 \%$ (car tires) and $23 \%$ (truck tires). This is due to the fact that reclaiming costs $c^{\mathrm{RF}}$ and disposal costs $c^{O}$ encompassed in the fee are added to the production costs whereas the OEM is not able to provide a counterpart on the sales side. The contribution margin improvements computed in scenario 2 have to be mitigated: despite the presence of retreaded tires, the marginal income per car tire shows no significant improvement for car tires. The component savings on casings are compensated by reintegration costs $c^{R}$ and lower prices for low-budget winter car tires (37 Euros instead of 45). Although summer car retreads are higher priced than import tires, their impact on the overall contribution margin is very limited because 
Table 6

Products' market share among scenarios in \%

\begin{tabular}{|c|c|c|c|c|c|c|c|c|}
\hline Scenario & & 0 & 1 & 2 & 3 & 4 & 5 & 6 \\
\hline \multirow[t]{4}{*}{ SCT } & High-end & 47.2 & 47.2 & 47.2 & 47.2 & 47.2 & 47.2 & 100 \\
\hline & Mid.-range & 35.2 & 35.2 & 35.2 & 35.2 & 35.2 & 35.2 & 0 \\
\hline & Import & 17.6 & 17.6 & 15.4 & 15.4 & 15.4 & 15.4 & 0 \\
\hline & Retread & 0 & 0 & 2.2 & 2.2 & 2.2 & 2.2 & 0 \\
\hline \multirow[t]{4}{*}{ WCT } & High-end & 39.45 & 39.45 & 39.45 & 39.45 & 39.45 & 39.45 & 100 \\
\hline & Mid.-range & 40.55 & 40.55 & 40.55 & 40.55 & 40.55 & 40.55 & 0 \\
\hline & Import & 20 & 20 & 7.5 & 8.9 & 7.5 & 7.5 & 0 \\
\hline & Retread & 0 & 0 & 12.5 & 11.1 & 12.5 & 12.5 & 0 \\
\hline \multirow[t]{4}{*}{ TT } & High-end & 37.8 & 37.8 & 37.8 & 37.8 & 37.8 & 37.8 & 100 \\
\hline & Mid.-range & 30 & 30 & 20 & 23.4 & 20 & 20 & 0 \\
\hline & Import & 32.2 & 32.2 & 0 & 0 & 0 & 0 & 0 \\
\hline & Retread & 0 & 0 & 42.2 & 38.8 & 42.2 & 42.2 & 0 \\
\hline
\end{tabular}

of their low market share $(2.2 \%)$. Truck retreads yield better prices than import ones and also induce important procurement savings through casing reuse. The remarkable increase of the marginal income between scenario 1 and $2(+42$ Euros/truck tire) is mostly explained by a higher average unit price $(+12$ Euros) coupled with component savings of 38 Euros/unit sold and disposal savings (3.5 Euros/tire).

Scenario 3, computing the impacts of a $50 \%$ returns loss, provides the most promising results in case of product stewardship since the marginal income per unit sold rises by $5.5 \%$ (SCT), 6.7\% (WCT) and by $10.3 \%$ for truck tires. Two facts are noticeable in this case: first, the marginal increase corresponds to the reclaiming cost savings. Furthermore, the market share of retreaded truck tires shrinks from $42.2 \%$ to $38.8 \%$, therefore indicating that not enough remanufacturable casings are returned. The remanufacturing bottleneck for truck tires in this scenario shifts from parameter $\beta$ to parameters $\theta$ and $\delta$, since not enough remanufacturable casings are available despite significant return rates. However, $\beta$ remains bottleneck in the car tire's case. The results of scenario 4 also underline that a preponement of the reverse flows has no positive impact on the contribution margin of the firm. By obtaining used tires earlier, a firm reclaims more tires during the planning time horizon. Unfortunately, this does

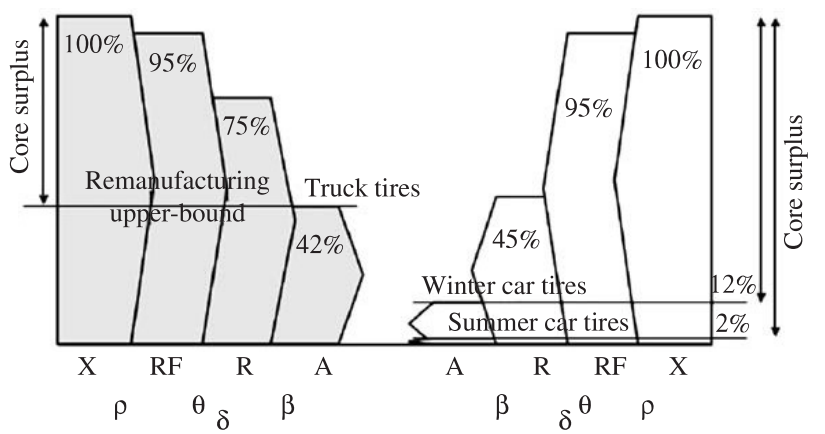

Fig. 6. Tire remanufacturing pipeline.

not lead to a remanufacturing rates improvement so that the tire surplus has to be disposed of (see Fig. 6). For the same reasons, a casing strengthening measure as in scenario 5 does not bring the positive effects expected: the additional costs in the first life-cycle cannot be amortized in the second cycle. Contribution margin differences to scenario 2 thereby have their origin in the component costs' increase, while the other profit and cost blocks remain stable. In order to benchmark the previous scenarios with the ideal case, we remove the market restrictions in scenario 6. Hence, it appears that an OEM should only sell high-end tires, notwithstanding which kind of tire he produces. While this hypothetic scenario is superior to every other scenario for car tires, scenario 3 provides a better margin income per truck tire sold, therefore 
indicating that a passive return strategy seems to be the right strategy for a truck tire OEM. The following figure, representing the remanufacturing pipeline, helps visualizing the influence of every key factor on the remanufacturing rate of a product and especially the bottleneck factor. In the best case, truck tires yield a market share of $42.2 \%$ while winter and summer car tires have an upper-bound of $12.5 \%$ and $2.2 \%$, respectively. Every measure aiming at increasing the remanufacturability of a product, as in scenarios $3-5$, will fail as long as the market share upper-bound has been already reached and will only generate a core surplus (see Fig. 6) that has to be either recycled, incinerated or landfilled.

Despite similar marginal income variations among scenarios, the car and truck tires differ with respect to the impact of retreaded tires. While the introduction of retreaded truck tires in all scenarios is obviously better than doing nothing in case of product stewardship $(+29 \%)$, the results are not clearly in favor of retreaded car tires. Given these results, it is not surprising to see truck tire manufacturers already active in the remanufacturing segment and praising the remanufacturability of their products (see for instance Continental Tire North America Inc. (2003) or Goodyear Inc. (2003)). Since the market potential of car retreads is much more restricted than in the truck tires' case, the hypothetic marginal income improvement per car tire is, for a majority of OEMs, not worth an integration by now.

\section{An explanation for tires' remanufacturing rate discrepancies based on $\beta^{\max }$}

The scenarios computed in the previous section have highlighted the fact that the profitability of tire remanufacturing programs obviously depends on the customers' acceptance for recovered products. The latter has been taken into account in our model through parameter $\beta$. Despite their identical product structure and recovery technologies, truck and car tires necessarily differ when it comes to customers' acceptance. Based on the observations in the tire industry, we draft a hypothesis arguing that products have functional (mostly of an objective nature) as well as psychosociological characteristics (mostly of a subjective nature). Given this, the success of remanufacturing is coupled with the dominance of functional aspects over psycho-sociological ones in the buying decision.

According to Kotler (2003), products are bought because of the utility they provide for the buyer. This utility is sourced in the ability to fill some needs, which Kotler separates into three different levels illustrated in Fig. 7: the core, the actual and the augmented product. While basic needs are covered through the initial functionality of a good (its core utility), OEMs tend to add and promote a subjective utility in order to improve their positioning and therefore achieve a distinct competitive edge. Car tires thereby provide a good example because the core function of a tire, which is to enable the movement of an object on a road, does not leave some room for differentiation. In fact, an observation of marketing campaigns for passenger car tires shows that only additional needs, mostly of subjective nature, are evoked. In Germany for instance, car tire manufacturers emphasize on security and design aspects while objective factors such as durability, rolling friction or price are seldom highlighted. This might be surprising as long as all new and retreaded tires sold in Europe have to comply with the same reliability requirements.

In contrast to car tires, cost and service aspects are especially pointed out when OEMs promote their truck tires. The services concerning the core product are gathered by Kotler to build another layer: the augmented product. These services, for

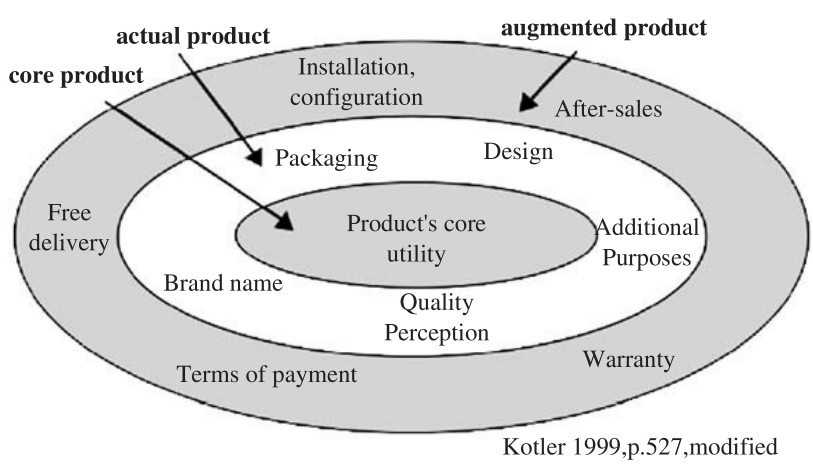

Fig. 7. Kotler's product levels concept (Kotler, 1999). 
example, consist of a buy-back program for used tires including discount offers for the procurement of new and retreaded truck tires. Thus, whereas the core and augmented product are predominating factors when selling truck tires, the actual product characteristics are decisive in the car tires' buying decision.

The discrepancy between summer and winter car tires can also be explained in a similar fashion. German customers expect to drive faster in summer than in winter so that they are more willing to buy winter retreads. This is, however, a subjective perception since the average speed on motorways remains constant over the year. Moreover, current speed limitations generally hinder car drivers to drive faster than $120-130 \mathrm{~km} / \mathrm{h}$ so that the upper-bound of $170 \mathrm{~km} / \mathrm{h}$ recommended for low-budget tires is far from being reached.

An incentive problem occurs when OEMs try to push their sales since they have to underscore subjective quality aspects in their marketing strategy. By promoting aspects such as prestige, modernity or security, they automatically tend to discredit remanufactured items. Furthermore, technology-based commodities such as mobile phones or, to a lesser extent, computers face short innovation cycles making previous product generations psychologically (through $\beta$ ) as well as functionally obsolete (through $\theta$ and $\delta$ ). This trend toward shorter product life cycles already depicted by Packard in the 60s (Packard, 1960) is obviously contradictory to component reintegration efforts. Unlike private customers, firms focus primarily on cost/performance ratios to guide their decisions. For this purpose, subjective utility is outweighed by price considerations and objective quality in the procurement phase of industrial commodities. The lack of psycho-sociological factors in the decision process hinders the raising of incentive problems between OEMs and buyers. In this context, we define functional products as goods for which only objective product characteristics and cost/performance aspects (gray-colored in Fig. 7) play a role in procurement decisions.

As a consequence, psycho-sociological products are goods for which subjective arguments tend to dominate buying decisions: $\beta^{\max }$ will often present the bottleneck for remanufactured products. High-

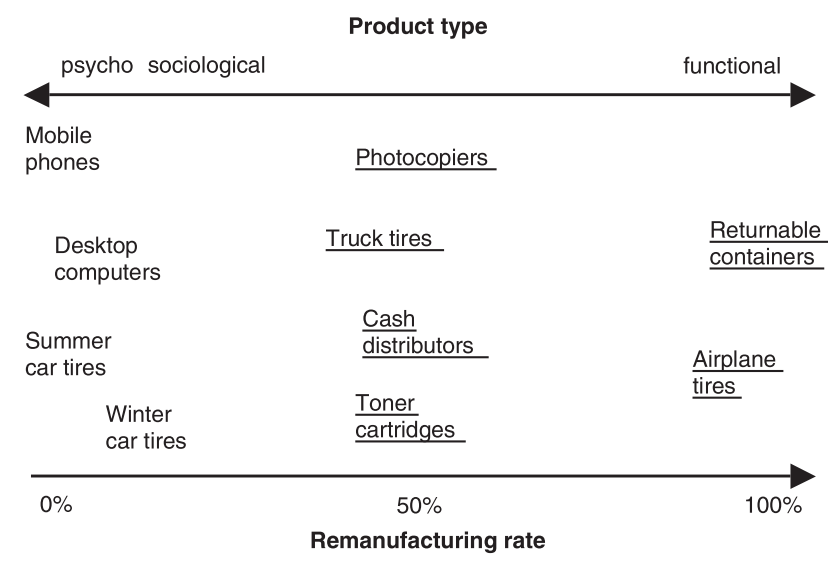

Fig. 8. Present remanufacturing rate for functional and psychosociological goods - (functional goods underlined).

range remanufacturing programs ought to emerge when no incentive problems exist. Therefore, we conclude that only functional products are relevant for component reintegration programs. Material recycling should be preferred for closing the supply chain of psycho-sociological commodities since remanufacturing seems not to be viable on a big scale. Fig. 8 recapitulates known case studies dealing with component-based recycling strategies. Thus, it is very interesting to notice that all important remanufacturing programs concern functional goods, therefore corroborating our hypothesis.

\section{Conclusion and outlook}

The purpose of this article was to present a reallife case study in which the profitability of remanufacturing operations could be investigated in a comprehensive way. Despite the uncertainty concerning the available data, the results obtained are in accordance with current market observations. Given the model output, the low budget segment provides significant growth potential in an already satured car tire market. Retreaded car and truck tires turn out to be a competitive alternative, although these face higher recovery costs. The observations of Ayres et al. (1997) related to the potential double-dividends thanks to tire retreading seem to be confirmed by our 
computations: the added value retained in a casing and reclaimed through remanufacturing reduces the manufacturing costs of a new tire while simultaneously improving the sustainability of the tire industry.

Unfortunately, tire retreading has already reached its limits with respect to the fraction of the demand willing to buy "green tires" eventually. To remove this demand bottleneck, one solution could be to underline the functional nature of a tire and to reduce the role of psycho-sociological factors in the procurement process. Otherwise, further measures aiming at increasing the amount of recoverable cores or measures addressing the ecological benefits of tires are not expected to influence the attractiveness of remanufactured items. Finally, since a $100 \%$ remanufacturing rate is neither technologically feasible nor economically justified, the goal of an OEM should be, thereby to determine an optimal return timing as well as quantities to avoid a core surplus. To the knowledge of the authors, research in this field is still under-represented.

\section{References}

ADAC, 2002. ADAC Motorwelt 10/2002.

Ayres, R.U., Ferrer, G., Van Leynseele, T., 1997. Ecoefficiency, asset recovery, and remanufacturing. European Management Journal 15 (5), 557-574.
Bundesverband, R., Vulkaniseur, H.e.V., 2000. Statistik, Markanteile der Reifenhersteller im Reifenersatzgeschäft, 1999.

Bundesverband R., Vulkaniseur H.e.V., 2001. Statistik: Der Markt für runderneuerte Reifen in Deutschland, 2000.

Continental Tire North America Inc., 2003. Form SS-HDR $01 / 03$.

Deierlein, R., 1988. Fleet feedback from buyers and specifierstire management. Fleet Equipment 11/1988, 43- 47.

Ferrer, G., 1997. The economics of tire remanufacturing. Resources, Conservation and Recycling 19, 221-255.

Geyer, R., Van Wassenhove, L.N., 2002. Remanufacturing products with limited component durability and finite life cycles. INSEAD Working Paper.

Goodyear Inc., 2003. Goodyear Retreads Handle Tough Terrain.

Guide, V.D.R., Van Wassenhove, L.N., 2001. Managing product returns for remanufacturing. Production and Operations Management 10 (2), 142-154.

Institut für Energie und Umweltforschung Heidelberg, 1999. Ökologische Bilanzen in der Abfallwirtschaft-Fallbeispiel Verwertung von Altreifen. Umweltbundesamt, Berlin.

Kotler, P., 1999. Grundlagen des Marketing, 2nd ed. PrenticeHall, Munich.

Kotler, P., 2003. Marketing Management, 11th ed. PrenticeHall, New York.

Kreislaufwirtschafts- und Abfallgesetz (KrW-/AbfG), 2001. In: Umweltrecht, 13th ed. DTV, Munich, pp. 295-329.

Lebreton, B., Tuma, A., 2003. Evaluating component recycling strategies. In: Voß, et al. (Eds.), Logistik Management. Prozesse, Systeme, Ausbildung. Physica, Heidelberg, pp. 333-347.

Packard, V., 1960. The Wastemakers. Penguin, New York.

Rogers, D., Tibben-Lembke, R.S., 1999. Going Backwards: Reverse Logistics Trends and Practices. Reverse Logistics Executive Council, Reno. 